\title{
A high-conversion gain, low-power mixer adapting current reuse technique for ZigBee application
}

\begin{abstract}
This paper presents a high-conversion gain, low-power, folded CMOS mixer for ZigBee application in $2.4 \mathrm{GHz}$ of user bandwidth. The proposed mixer adapts current reuse technique to increase the conversion gain while substantially reducing the DC power dissipation. The current from LO stage is reused at the transconductance stage to reduce the power consumption. This mixer is verified in $0.13 \mu \mathrm{m}$ standard CMOS technology. The simulation result exhibits a high-conversion gain performance (CG) of $10 \mathrm{~dB}, 1 \mathrm{~dB}$ compression point (P1 dB) of $-13.43 \mathrm{dBm}$, third-order intercept point (IIP3) of $-4.3 \mathrm{dBm}$, and a noise figure of $16.67 \mathrm{~dB}$. The circuit draws $675 \mu \mathrm{A}$ current from the $1.2 \mathrm{~V}$ of supply voltage headroom.
\end{abstract}

Keyword: Complementary metal-oxide semiconductor; Current reused; High-conversion gain; Mixer; ZigBee 